\title{
Diabetes MILES-Australia (management and impact for long-term empowerment and success): methods and sample characteristics of a national survey of the psychological aspects of living with type 1 or type 2 diabetes in Australian adults
}

\author{
Jane Speight ${ }^{1,2,3^{*}}$, Jessica L Browne ${ }^{1,2}$, Elizabeth Holmes-Truscott ${ }^{1,2}$, Christel Hendrieckx ${ }^{1,2}$ and Frans Pouwer ${ }^{4}$
}

\begin{abstract}
Background: Successful management of diabetes requires attention to the behavioural, psychological and social aspects of this progressive condition. The Diabetes MILES (Management and Impact for Long-term Empowerment and Success) Study is an international collaborative. Diabetes MILES-Australia, the first Diabetes MILES initiative to be undertaken, was a national survey of adults living with type 1 or type 2 diabetes in Australia. The aim of this study was to gather data that will provide insights into how Australians manage their diabetes, the support they receive and the impact of diabetes on their lives, as well as to use the data to validate new diabetes outcome measures.

Methods/design: The survey was designed to include a core set of self-report measures, as well as modules specific to diabetes type or management regimens. Other measures or items were included in only half of the surveys. Cognitive debriefing interviews with 20 participants ensured the survey content was relevant and easily understood. In July 2011, the survey was posted to 15,000 adults (aged 18-70 years) with type 1 or type 2 diabetes selected randomly from the National Diabetes Services Scheme (NDSS) database. An online version of the survey was advertised nationally. A total of 3,338 eligible Australians took part; most (70.4\%) completed the postal survey. Respondents of both diabetes types and genders, and of all ages, were adequately represented in both the postal and online survey sub-samples. More people with type 2 diabetes than type 1 diabetes took part in Diabetes MILES-Australia (58.8\% versus 41.2\%). Most respondents spoke English as their main language, were married/in a de facto relationship, had at least a high school education, were occupied in paid work, had an annual household income $>\$ A U S 40,000$, and lived in metropolitan areas.
\end{abstract}

Discussion: A potential limitation of the study is the under-representation of respondents from culturally and linguistically diverse backgrounds (including Aboriginal and Torres Strait Islander origin). Diabetes MILES-Australia represents a major achievement in the study of diabetes in Australia, where for the first time, the focus is on psychosocial and behavioural aspects of this condition at a national level.

Keywords: Diabetes, Psychology, National survey, Self-care, Quality of life, Diabetes-related distress, Depression

\footnotetext{
* Correspondence: jspeight@acbrd.org.au

${ }^{1}$ The Australian Centre for Behavioural Research in Diabetes, Diabetes

Australia-Vic, 570 Elizabeth Street, Melbourne, VIC 3000, Australia

Full list of author information is available at the end of the article
}

(c) 2012 Speight et al; BioMed Central Ltd. This is an Open Access article distributed under the terms of the Creative Commons 


\section{Background}

Diabetes is a common and progressive long-term condition, which places a significant burden of self-management on the individual. The prevalence of all types of diabetes is increasing, with type 2 diabetes growing at epidemic proportions [1]. The total number of people with diabetes worldwide was conservatively estimated to increase from 171 million in 2000 to 366 million in 2030 [2].

Self-management of diabetes (in all its forms) is a complex behavioural and social process, requiring not only a comprehensive understanding of the condition but also high levels of self-efficacy, perceived control and empowerment [3]. Unsurprisingly, having diabetes can negatively impact the quality of life of people living with the condition $[4,5]$. A considerable number of studies have found relatively high levels of distress, and, in a substantial minority, significant depressive symptomatology [6]. Furthermore, the onset of complications (such as retinopathy, neuropathy, kidney damage, heart disease and stroke) can exacerbate the psychological impact of this progressive condition [7]. Thus, the association between diabetes and psychological burden appears to be a vicious cycle and we need to identify ways to reduce this burden. In addition to understanding the psychological health and well-being of people with diabetes, research is needed to establish a greater understanding of perceptions and misconceptions among people with diabetes, their health beliefs and the personal values which inform their self-management.

Such research has been concentrated for the most part in the US and Europe, with very little being conducted in Australia. The Diabetes Attitudes Wishes and Needs (DAWN) Study is probably the only large-scale study that has focused on the psychological impact of diabetes and the implications for improvements to health care for people with diabetes [8]. This cross-national study, which included an Australian sample, highlighted the importance of a positive and collaborative relationship between health care providers and people with diabetes [9], as well as the relatively high prevalence of diabetesrelated distress amongst people with diabetes [10], and the role of psychological and social barriers to self-care and medication initiation and management $[11,12]$. The DAWN Study highlighted important avenues for future research into the psychological aspects of living with diabetes that need to be pursued in Australia. DAWN 2, a related study with increased breadth, is currently underway but Australia is not included in this new initiative.

The Living With Diabetes Study is a population-based cohort study of the quality of life and well-being of people with diabetes living in Queensland, Australia [13].
One of the primary aims of this study is to evaluate a state-based strategy for the management of chronic conditions, and thus the Living With Diabetes Study has been undertaken in one Australian state only.

The Diabetes MILES Study has been established as an international collaborative, the aim of which is to conduct a series of national surveys of people with type 1 or type 2 diabetes in various countries. Diabetes MILES-Australia is the first Diabetes MILES initiative, and was conceived to provide a national survey of the psychological health, self-care beliefs and activities, and unmet needs of Australians living with type 1 or type 2 diabetes. The Diabetes MILES-Australia 2011 survey was built on four central themes: management, impact, empowerment, and success.

\section{Survey themes \\ Management}

The burden of the management of diabetes falls largely to the individual living with the condition. Self-management, or self-care, activities are crucial for achieving and maintaining optimal blood glucose levels, and preventing diabetes-related complications. Self-care is defined as 'activities that individuals, families and communities undertake with the intention of enhancing health, preventing disease, limiting illness and restoring health. They are undertaken by lay people on their own behalf, either separately or in participative collaboration with health professionals' [14]. Diabetes self-care can involve dietary modifications, taking medications as recommended, regular physical activity, foot care and selfmonitoring of blood glucose.

Self-care requires not only a comprehensive understanding of diabetes but also belief in one's capabilities, motivation to perform complex self-care activities, and a supportive environment (of family, friends and health care professionals). Self-care is central to both the experience of living with diabetes and the optimisation of diabetes outcomes, and thus ongoing research in this area is essential.

\section{Impact}

International reviews have found clinical levels of depression in up to $12 \%$ of people with type 1 diabetes and $18 \%$ of people with type $2[15,16]$. Many more are likely to report some level of diabetes-related distress [6] and, on average, diabetes has a negative impact on quality of life [5]. Understanding the psychological, emotional, and social impact of diabetes is essential for the development and evaluation of new therapies and interventions, including but not limited to psychological therapies. For example, identifying the negative impact of diabetes on dietary freedom [5] was instrumental in hypothesising that the Dose Adjustment For Normal 
Eating (DAFNE) program [17] would offer substantial benefits for quality of life, benefits which have been well-maintained for up to four years in combination with partially maintained improvements in glycaemic levels [18]. We need to advance our understanding of the psychological, emotional, and social impact of diabetes so that care and support for people living with the condition can be optimised.

\section{Empowerment}

A person with diabetes who is empowered has high perceived self-efficacy, is actively engaged in their own health care (including self-care), and seeks out necessary support and information. Empowerment is undoubtedly philosophically desirable, and importantly, evidence suggests that it is the only way to achieve optimal, sustainable longterm outcomes [19]. Unfortunately, it can be rare in everyday clinical practice, where both the health care professional and person with diabetes often adopt traditional roles, which can result in the person with diabetes becoming a passive recipient of health care and feeling de-motivated. Access to diabetes education and utilisation of healthcare resources are examples of the means through which people with diabetes can be empowered to best manage their condition, and both are critical in achieving optimal biomedical outcomes in diabetes. Education and support programs are known to enhance self-management and improve psychosocial outcomes but are not widely available. Figures from the UK national diabetes audit [20] indicate that a large proportion of people with diabetes are not undergoing the regular checks recommended for careful monitoring of their condition. It is important to understand the role of empowerment in successful diabetes management and utilisation of services, and to subsequently promote and facilitate patient empowerment in health care and other settings.

\section{Success}

In addition to understanding the psychological health and well-being of Australians with diabetes, research is needed to develop a greater understanding of the role of health beliefs, and the personal values which inform self-management and willingness to engage with treatments as recommended by health care professionals. Health beliefs (e.g. perceived severity of disease, perceived efficacy of treatment) and aspects of positive mental health (such as resilience, self-esteem, optimism) are important mediators of diabetes outcomes [21-23]. Hardiness, is associated with lower distress; low rates of complications and is a good predictor of optimal outcomes, independent of education [22]. Social and peer support is also implicated in better outcomes $[24,25]$. It is important to further examine the role of a person's disposition, and their social context, in contributing to living successfully with diabetes [26].
Aims

The primary aims of Diabetes MILES-Australia are to:

- conduct a large-scale survey of Australian adults with type 1 or type 2 diabetes with a focus on exploring the psychological, behavioural and social factors relevant to living with diabetes

- ensure the suitability of the survey as the baseline for a longitudinal (repeated cross-sectional and cohort) study

- use the results to raise awareness of the psychological health and unmet needs of Australian adults living with diabetes.

Primary research questions to be addressed by Diabetes MILES-Australia include (but are not limited to):

- What characterises living successfully with diabetes? (e.g. long diabetes duration with minimal physical complications and optimal psychological health)

- What is the prevalence of impaired awareness of hypoglycaemia and severe hypoglycaemia among people with type 1 diabetes?

- What are unmet needs of Australian adults living with diabetes?

- What is the impact of diabetes on the well-being of Australians living with the condition?

- Is the Quality of Life Questionnaire-Diabetes [27] a valid and reliable measure of the impact of diabetes on quality of life?

- Is the Diabetes Self-Care Inventory-Revised a valid and reliable measure of self-care beliefs, attitudes, and behaviours?

- Are postal and internet-based surveys equally suitable methods for conducting a national survey?

- How do two measures of diabetes-related distress (the Diabetes Distress Scale (DDS)[28] and the Problem Areas In Diabetes questionnaire (PAID)[29]) compare in terms of psychometric properties and utility?

- What is the prevalence of clinically significant depression, anxiety and diabetes-related distress in Australian adults living with diabetes?

\section{Methods/design}

\section{Ethics approval}

Ethics approval was granted by Deakin University Human Research Ethics Committee (reference number 2011-046). A plain language statement and consent form were developed for the cognitive debriefing phase as well as for the main national survey. 


\section{Establishment of the reference group}

A multidisciplinary reference group was established comprising 32 representatives from psychology, nursing, population health, health economics, pharmacy, endocrinology, and general practice (see http://www.diabetesMILES.org). Most reference group members are Australian but eight international academics are also involved. The role of the reference group was to advise on survey content (concepts, measures and individual variables) and research questions. An important ongoing role for the reference group is to collaborate on dissemination of the survey results.

\section{Phase 1: Selection of psychological measures}

The Diabetes MILES-Australia 2011 survey was developed through the following process: initial measure selection occurred after phases of measure identification, assessment and consultation, cognitive debriefing of standardised measures and survey-specific items before survey distribution.

\section{Identification}

Within each study theme (management, impact, empowerment and success) a number of relevant concepts were identified. For each concept a questionnaire search was completed. Measures were considered for use only if they were appropriate for use with adults (aged 18-70 years) and were designed for any of the following population types: generic, diabetes specific, chronic condition specific.

\section{Assessment}

For each measure the following information was collected and assessed: length, reliability and validity, previous use in Australia and internationally, and use within diabetes-specific populations.

A number of important concepts of the study were not adequately or succinctly measured through already established questionnaires, necessitating the drafting of a number of items by the research team at this point. It became clear that several measures had not been validated for use in Australia but one of the pivotal roles of Diabetes MILES-Australia is to provide the dataset upon which psychometric validation can be conducted. Linguistic validation (i.e. the extent to which measures were suitable for use in English for Australia) was considered during selection by the research team (two of whom are Australian) and through cognitive debriefing (see below) with Australians living with diabetes.

\section{Consultation}

After the initial assessment had been made, an itembank was compiled for consideration by the wider reference group who were asked to contribute detailed feedback and suggestions for further development of the item-bank. The item-bank was circulated for consultation three times. On each occasion the feedback received either confirmed the use of an identified measure or led to identification and assessment of other measures. The Principal Investigator (JS) and the research team made all final decisions regarding the survey content.

\section{Phase 2: Pilot study and cognitive debriefing}

The aim of the pilot study was to ensure that the survey content was relevant and suitable for Australian adults with type 1 or type 2 diabetes. This involved asking participants to complete the survey and then take part in a cognitive debriefing (CD) interview.

\section{Recruitment}

Participants were recruited through advertisements in relevant diabetes media (Diabetes Australia-Vic magazines, websites and e-newsletters) in the state of Victoria. Potential participants contacted the research team by telephone or email and they were sent (by email, post or fax) a copy of the plain language statement, and a consent form to sign. Participants were eligible if they met the inclusion criteria for the larger national survey sample (see below). Decisions regarding recruitment were based on responses to a brief set of screening questions. This ensured a representative sample, relevant to the aims of this phase of the study (i.e. an adequate mix of men/women, ages, diabetes types and treatment, education levels and occupations). In addition, participants needed to be willing to attend interviews held in Melbourne city centre, Burwood (suburb of Melbourne) or Geelong (regional city in Victoria, although no participants chose this option) to minimise travel expenses and to enable this phase of the project to progress quickly.

\section{Procedure}

Ahead of the CD session, participants were posted a copy of the survey booklet plus a letter requesting that they read and/or complete the survey booklet no more than one day before the interview. Participants were invited to make note of any survey instructions, sections, questions or response options which were unclear or of concern to them. Upon arrival at the CD session, participants were asked to provide their consent form and were reminded of their participatory rights. All interviews were audio recorded in a de-identified digital format. Participants were free to refuse to answer any of the questions.

Participants were first asked to comment on the survey as a whole in terms of relevance, readability, acceptability, language and length. Participants were also asked how long it took them to complete the survey and the extent to which they found it easy or difficult to complete. Participants were then asked a number of similar questions about each section of the survey, a selection of specific standardised psychological measures, and study-specific items. 


\section{Results}

CD was conducted with 20 adults living in and around Melbourne: 12 participants with type 1 diabetes (seven women; mean age $=43.5 \pm 9.6$ years (range: $25-56$ years)); eight with type 2 diabetes (seven women; mean age $=55.9 \pm 15.2$ years (range: $21-64$ years)). The education level of participants ranged from secondary school to higher university degree.

Participants indicated that it took a mean of $58 \mathrm{~min}$ to complete or read through the survey (range: 20-120 min). The CD interviews had a mean duration of 51 min (range: 20-109 $\mathrm{min}$ ).

Some minor changes to the survey were made in response to feedback received, such as improvements to the survey booklet layout, amending instructions so they were simpler and more consistent, and a small number of measures were excluded from the survey to reduce its length.

\section{Phase 3: Finalising survey content and study materials}

All survey modifications made as a result of the CD sessions were approved by the Deakin University Human Research Ethics Committee.

At the completion of this process the detailed concept and measure index (Table 1) was finalised. This index lists all concepts investigated in the Diabetes MILESAustralia 2011 survey, the measures used to assess these concepts, as well as the survey version in which the measure was included. Minimising respondent burden and maximising relevance (e.g. to diabetes type/treatment) were crucial considerations. Thus, the item bank was split into six surveys: an 'A' and 'B' version for each participant group (type 1 diabetes (T1), type 2 diabetes insulin-treated (T2I), type 2 diabetes non-insulin-treated (T2)). This enabled inclusion of some questionnaires which may have otherwise been excluded due to space limitations. Core measures/items were included in all survey versions, while others were included in only one or two versions (details in Table 1). Completion of the survey was expected to take approximately one hour.

\section{Preparation of postal and online surveys}

Hard copy and online versions of the survey were developed. A contract research organisation (CRO) prepared the hard copy survey booklets in a format that enabled responses to be scanned for automated data entry. The online survey was designed by a web developer based in the School of Psychology, Deakin University.

The postal survey booklets (specific to diabetes type and treatment regimen of recipient; version A or B randomly assigned) were packaged with a reply-paid envelope, a plain language statement and withdrawal of consent form, contact details form and a language other than English (LOTE) form (both optional to complete). For practical reasons, the survey was not available in
LOTE but survey recipients were invited to indicate if they would like to complete a similar survey in their own language in the future (if it became available). This statement was translated into nine of the most commonly spoken languages in Australia: Arabic, Cantonese, Greek, Italian, Macedonian, Mandarin, Spanish, Turkish, and Vietnamese.

\section{Phase 4a: Data collection-national postal survey}

Approximately six weeks was allocated for data collection (postal survey distribution and return, and online completion).

\section{Study population}

The postal survey was distributed to a random sample of 15,000 registrants of the National Diabetes Services Scheme (NDSS). The NDSS register includes approximately one million Australians diagnosed with diabetes (e.g. type 1, type 2, gestational). NDSS registrants were eligible for selection if they met the following inclusion criteria:

- living with type 1 or type 2 diabetes

- aged 18 to 70 years

- previously indicated consent to be contacted about future research; approximately 250,000 (25\%) of NDSS registrants

The sample size of 15,000 was chosen in anticipation of a $20 \%$ response rate $(\mathrm{N}=3,000)$, offering a substantial dataset and enabling meaningful subgroup analyses. The sample was stratified (based on information provided on the NDSS register) to ensure adequate representation of specific types of diabetes and treatment regimens:

- Type 1 diabetes: 6,000 registrants (40\% of total sample)

- 5,400 using insulin injections

- 600 using pump therapy

- Type 2 diabetes: 9,000 registrants (60\% of total sample)

- 4,500 using insulin

- 4,500 not using insulin

The sample was not stratified by gender.

\section{Procedure}

All study materials were supplied to the Diabetes Australia-Vic mail co-ordination team who addressed and posted all surveys. The research team had no direct involvement in the random selection or in the handling of potential participant contact details.

Participants received the survey package by post and were asked to return the completed survey using the reply-paid envelope provided before $31^{\text {st }}$ July 2011. In 
Table 1 Concepts, measures and variables included in the Diabetes MILES-Australia 2011 Survey

\begin{tabular}{|c|c|c|}
\hline Concept & Measure or variable & $\begin{array}{l}\text { Survey } \\
\text { version }\end{array}$ \\
\hline \multicolumn{3}{|l|}{ Part 1: Your feelings In general } \\
\hline Subjective Wellbeing & PWI: Personal Wellbeing Index [30] & ALL \\
\hline Emotional Wellbeing & WHO-5: World Health Organisation Well-being index [31] & ALL \\
\hline Depression & PHQ-9: Patient Health Questionnaire [32]^ & ALL \\
\hline Anxiety & GAD-7: General Anxiety Disorder Questionnaire [33]^ & ALL \\
\hline \multicolumn{3}{|c|}{ Part 2: Your feelings about diabetes } \\
\hline $\begin{array}{l}\text { Diabetes specific quality of } \\
\text { life }\end{array}$ & QoL-Q Diabetes [27] & ALL \\
\hline Diabetes-specific distress & DDS: Diabetes Distress Screening Scale [28] ; PAID: Problem Areas In Diabetes scale [29] ${ }^{\#} \wedge$ & ALL \\
\hline $\begin{array}{l}\text { Diabetes-specific positive } \\
\text { well-being }\end{array}$ & 4-item subscale of the W-BQ28: Wellbeing Questionnaire [34] & ALL \\
\hline \multicolumn{3}{|l|}{ Part 3: Your general health } \\
\hline General health & EQ5D-5L [35]; 3 items (general health in past 4 weeks; change in health in past year)* & ALL \\
\hline Miscellaneous & 7 items: other conditions/co-morbidities*^; sleep*; transplants*; dialysis*; weight loss surgery* & ALL \\
\hline \multicolumn{3}{|c|}{ Part 4: Support from health professionals } \\
\hline Health consultations & $\begin{array}{l}29 \text { items (main health care professionals, access, reliance, distance, consistency, continuity, distance/cost } \\
\text { as an obstacle, timely appointment attendance)*^ inspired by the ALSHW Survey } 2009\end{array}$ & ALL \\
\hline $\begin{array}{l}\text { Healthcare and self- } \\
\text { management }\end{array}$ & RSSM: Resources and Support for chronic illness Self-Management scale [36] & $\begin{array}{l}\text { T1A, T2IA, } \\
\text { T2A }\end{array}$ \\
\hline Structured education & 4 items* inspired by the IDF Diabetes Atlas 2009 & $\begin{array}{l}\text { T1A, T2IA, } \\
\text { T2A }\end{array}$ \\
\hline Empowerment & DES-SF: Diabetes Empowerment Scale Short Form [37] & ALL \\
\hline Health literacy & HeLMS: Health Literacy Management Scale (seven of eight subscales included) & ALL \\
\hline \multicolumn{3}{|c|}{ Part 5: Support from friends and family } \\
\hline Peer/family support & $\begin{array}{l}3 \text { items* inspired by Tang et al, } 2008 \text { [38]; DFSC: Diabetes Family Support and Conflict [39], Diabetes } \\
\text { support group involvement* }\end{array}$ & $\begin{array}{l}\mathrm{T} 1 \mathrm{~B}, \mathrm{~T} 2 \mathrm{~B}, \\
\mathrm{~T} 2 \mathrm{~B}\end{array}$ \\
\hline \multicolumn{3}{|l|}{ Part 6: Your diabetes } \\
\hline Diabetes history & Age at diagnosis ${ }^{*}$; diabetes type* $\wedge$; current treatment regimen*^ & ALL \\
\hline $\begin{array}{l}\text { Blood glucose monitoring } \\
\text { and recording }\end{array}$ & $\begin{array}{l}6 \text { items (satisfaction, monitoring, recording, action)* inspired by the DAFNE self-management } \\
\text { questionnaire (in development)* }\end{array}$ & ALL \\
\hline $\begin{array}{l}\text { Self-care behaviours \& } \\
\text { attitudes }\end{array}$ & $\begin{array}{l}\text { Diabetes Self-Care Inventory-Revised^ adapted to include smoking items* inspired by the Smoking and } \\
\text { Health Survey } 2010 \text { (the Cancer Council Vic)[40] }\end{array}$ & ALL \\
\hline Medication adherence & MARS: Medication Adherence Rating Scales [41] (Insulin and/or Medicine) & ALL \\
\hline $\begin{array}{l}\text { Blood glucose level and } \\
\mathrm{HbA1} 1_{C} \text { targets }\end{array}$ & 4 items $^{*} \wedge$ & $\begin{array}{l}\text { T1A, T2IA, } \\
\text { T2A }\end{array}$ \\
\hline Hypoglycaemia awareness & The Gold Score [42]; 5 items from the HypoA-Q: Hypo Awareness Questionnaire [43]^ & $\mathrm{T} 1 \mathrm{~A}$ \\
\hline Hypoglycaemia treatment & 1 item* & T1A \\
\hline Fear of hypoglycaemia & 2 items* inspired by the Hypoglycaemia Fear Scale [44] & T1A \\
\hline Insulin restriction & $\begin{array}{l}\text { Items inspired by Diabetes Australia-Vic's Type } 1 \text { Diabetes and Eating Disorders Online Survey } 2008 \\
\text { Report* }\end{array}$ & T1B \\
\hline Disordered eating & 6 items* inspired by Type 1 Diabetes and Eating Disorders Online Survey 2008 report & T1B \\
\hline $\begin{array}{l}\text { Perceived behavioural } \\
\text { control }\end{array}$ & 15 items* & $\mathrm{T} 2 \mathrm{IB}, \mathrm{T} 2 \mathrm{~B}$ \\
\hline Physical activity & IPAQ: International Physical Activity Questionnaire (Short Form) [45]; 5 items* & $\mathrm{T} 2 \mathrm{IB}, \mathrm{T} 2 \mathrm{~B}$ \\
\hline $\begin{array}{l}\text { Psychological insulin } \\
\text { resistance }\end{array}$ & ITAS: Insulin Treatment Appraisal Scale [46] ${ }^{\wedge}$ & $\mathrm{T} 2 \mathrm{IB}, \mathrm{T} 2 \mathrm{~A}$ \\
\hline \multicolumn{3}{|c|}{ Part 7: Your thoughts and beliefs } \\
\hline Optimism & LOT-R: Life Orientation Test-Revised [47] & $\begin{array}{l}\text { T1B, } \mathrm{T} 2 \mathrm{IB}, \\
\mathrm{T} 2 \mathrm{~B}\end{array}$ \\
\hline
\end{tabular}


to the CRO for merging with the postal survey data. The CRO then provided the research team with a data file that contained the data from all returned surveys (postal and online), plus scanned images of each page of all postal surveys. All hard copies of the survey booklets were returned to the research team for secure storage.

Statistical analyses will be performed using the Statistical Package for the Social Sciences (SPSS) version 17.0. Given the anticipated large sample size, Bonferroni corrections will be used to apply more conservative significance levels for all analyses. Differences between subgroups will be determined using $\chi^{2}$ tests for categorical data and independent samples t-tests or ANOVAs for continuous variables. Further analyses (e.g. principal components analysis, multiple regression) may be used dependent on specific research questions and will be reported in subsequent papers as relevant. Sample characteristics are presented below using frequencies (N (\%)) for categorical variables and mean \pm standard deviation for continuous variables.

\section{Response rates}

In total, 3,833 people responded to the Diabetes MILES-Australia 2011 survey:

- 987 completed the online survey, of which 220 participants indicated that they had received the postal survey.

- 2,351 completed the postal survey or responded to the online survey after receiving the postal version, a response rate of $17 \%$. However, 541 postal surveys were returned to sender, as the addressee was no longer at the address provided by the NDSS, or was deceased. Thus, the adjusted response rate is $18 \%$.

Of the total 3,833 respondents, 495 did not meet all of the eligibility criteria (e.g. did not have type 1 or type 2 diabetes, aged younger than 18 or older than 70, could not complete survey in English without assistance) and were excluded from the sample. Subsequent analyses presented in this and other papers arising from Diabetes MILES-Australia refer only to the final sample of 3,338 eligible respondents. Response rates of eligible participants for the postal versus online surveys are presented in Table 2.

The representativeness of the sample can be determined by comparing respondents on key characteristics to NDSS registrants. More than half (58\%) of the Diabetes MILES-Australia sample was from the states of New South Wales or Victoria and by comparison, 59\% of NDSS registrants are from these two states ${ }^{\text {a }}$. Substantially smaller proportions of people from other Australian states and territories are NDSS registrants, and this was also reflected in our study sample. Nationally, 53\% of NDSS registrants are men, as compared to $46 \%$ of our study sample, suggesting that women were slightly over-sampled in the Diabetes MILES-Australia study ${ }^{\mathrm{b}}$.

\section{Sample characteristics}

Respondents were asked to indicate their diabetes type as well as to provide a range of demographic information (see Table 3). People with type 2 diabetes were more highly represented in the sample than people with type 1 (58.8\% versus $41.2 \%$ ), proportionate to the ratio of surveys distributed (60\% versus $40 \%$ respectively). Men and women were represented almost equally in the sample $(46.2 \%$ versus $53.8 \%$ respectively). Most respondents spoke English as their main language, were married or in a de facto relationship, had at least a high school education, lived in metropolitan areas, were occupied in paid employment, and had an annual household income of more than \$AUS40,000 (approximately \$US39,600 or $€ 30,563$ ) per annum. Only a very small proportion (1.7\%) of respondents were from an Aboriginal and/or Torres Strait Islander (ATSI) background, and only $3 \%$ of the total sample indicated that they mainly spoke a language other than English at home. However, 25.4\% of respondents indicated that they were born in a country other than Australia, which is representative of the broader Australian population [53].

\section{Qualitative feedback}

Participants who took part in the CD interviews identified that this study "is not trying to understand [diabetes] from a medical point of view but from a psychological point of view...because depression and diabetes...are best of friends" (male, 25 years, type 1 diabetes). We found that people with diabetes were frustrated with the current health 'system' and that this survey asked questions which "usually no one asks" (female, 58 years, type 2 diabetes). The "questions were quite probing...they scratched beneath the surface" (male, 44 years, type 1 diabetes). One individual commented "someone has finally done it...its needed.... there's so much frustration... within the diabetic system.... when's it's all put together in voice and collected as a whole it's easy to get out there"(male, 25 years, type 1 diabetes). Overall, Diabetes MILES-Australia has received a great deal of positive feedback from people with diabetes.

\section{Discussion}

To our knowledge, Diabetes MILES-Australia is the largest national survey of the impact of living with diabetes ever performed in Australia; the largest in terms of sample size but also in terms of the breadth and depth of questioning. Diabetes MILES-Australia represents the first opportunity of its kind to assess the psychological 
Table 2 Response rates for postal versus online survey*

\begin{tabular}{|c|c|c|c|}
\hline State/territory & Total respondents $\mathrm{N}(\%)$ & Respondents to postal survey N (\%) & Respondents to online survey $\mathrm{N}(\%)$ \\
\hline Total sample & $3338(100)$ & $2351(70.4)$ & $987(29.6)$ \\
\hline Type 1 diabetes & $1376(41.2)$ & $865(36.8)$ & $511(51.8)$ \\
\hline $\mathrm{ACT}$ & $39(1.2)$ & $17(0.7)$ & $22(2.3)$ \\
\hline NSW & $295(9.0)$ & $233(10.0)$ & $62(6.4)$ \\
\hline NT & $19(0.6)$ & $19(0.8)$ & $0(0.0)$ \\
\hline QLD & $266(8.1)$ & $203(8.7)$ & $63(6.5)$ \\
\hline SA & $68(2.1)$ & $53(2.3)$ & $15(1.6)$ \\
\hline TAS & $30(0.9)$ & $21(0.9)$ & $9(0.9)$ \\
\hline $\mathrm{VIC}$ & $497(15.1)$ & $200(8.6)$ & $297(30.9)$ \\
\hline WA & $137(4.2)$ & $113(4.8)$ & $24(2.5)$ \\
\hline Type 2 diabetes & $1962(58.8)$ & $1486(63.2)$ & $476(48.2)$ \\
\hline $\mathrm{ACT}$ & $28(0.8)$ & $22(0.9)$ & $6(0.6)$ \\
\hline NSW & $477(14.5)$ & 427 (18.3) & $50(5.2)$ \\
\hline NT & $66(2.0)$ & $66(2.8)$ & $0(0.0)$ \\
\hline QLD & 327 (9.9) & $284(12.2)$ & $43(4.5)$ \\
\hline SA & $135(4.1)$ & $130(5.6)$ & $5(0.5)$ \\
\hline TAS & $64(1.9)$ & $59(2.5)$ & $5(0.5)$ \\
\hline $\mathrm{VIC}$ & 646 (19.6) & $328(14.1)$ & $318(33.1)$ \\
\hline WA & $199(6.0)$ & $156(6.7)$ & $43(4.5)$ \\
\hline Men & 1525 (46.2) & $1137(48.9)$ & 387 (39.6) \\
\hline $18-24$ years & $47(1.4)$ & $37(1.6)$ & $10(1.0)$ \\
\hline 25-34 years & 103 (3.1) & $70(3.0)$ & $33(3.4)$ \\
\hline $35-44$ years & 152 (4.6) & $106(4.6)$ & $46(4.7)$ \\
\hline 45-54 years & $292(8.8)$ & 206 (8.9) & $86(8.8)$ \\
\hline 55-64 years & $560(17.0)$ & 408 (17.6) & $152(15.5)$ \\
\hline $65-70$ years & $370(11.2)$ & 310 (13.3) & $60(6.1)$ \\
\hline Women & $1778(53.8)$ & $1187(51.1)$ & $591(60.4)$ \\
\hline $18-24$ years & 126 (3.8) & $94(4.0)$ & $32(3.3)$ \\
\hline 25-34 years & $226(6.8)$ & $128(5.5)$ & $98(10.0)$ \\
\hline $35-44$ years & $259(7.8)$ & $150(6.5)$ & 109 (11.1) \\
\hline 45-54 years & 387 (11.7) & $237(10.2)$ & $150(15.3)$ \\
\hline 55-64 years & $502(15.2)$ & 355 (15.3) & 147 (15.0) \\
\hline $65-70$ years & 278 (8.4) & 223 (9.6) & $55(5.6)$ \\
\hline
\end{tabular}

ACT: Australian Capital Territory; NSW: New South Wales; NT: Northern Territory; QLD: Queensland; SA: South Australia; TAS: Tasmania; VIC: Victoria; WA: Western Australia

* Table refers only to eligible participants. Total $\mathrm{N}$ is not always consistent with total sample size due to missing data on some items

health and unmet needs of a large and diverse sample of Australian adults with type 1 or type 2 diabetes. The dissemination of findings from Diabetes MILES-Australia over several years will raise awareness of the psychological and social impact of diabetes, as well as highlighting key associations between factors such as health status, health beliefs, social support, self-care, empowerment and a range of psychological outcomes. Findings will inform future research projects specific to the needs of Australians with diabetes and provide information that will assist in improving the capability of the NDSS to meet the needs of its registrants. Diabetes MILES-Australia, as described here, also represents the first step towards establishing a longitudinal program of research.

Diabetes MILES-Australia has been met with considerable enthusiasm by people with diabetes in Australia. Many participants commented on the significance of the study for them personally and for people with diabetes generally. Both the survey and the cognitive debriefing 
Table 3 Sample characteristics: Diabetes MILES-Australia 2011 cohort

\begin{tabular}{|c|c|c|c|}
\hline & \multicolumn{3}{|c|}{$\mathrm{N}(\%)$ or Mean \pm SD (Range) } \\
\hline & Type 1 & Type 2 N (\%) & Total $N^{*}(\%)$ \\
\hline TOTAL & $1376(41.2)$ & $1962(58.8)$ & $3338(100)$ \\
\hline Gender-female & $825(60.6)$ & $953(49.1)$ & $1778(53.8)$ \\
\hline Age-years & $41.98 \pm 13.96(18-70)$ & $58.55 \pm 8.71(19-70)$ & $51.71 \pm 13.84(18-70)$ \\
\hline Aboriginal or Torres Strait Islander origin & $10(1.0)$ & $39(2.1)$ & $49(1.7)$ \\
\hline Main language spoken at home-English & $1322(96.1)$ & $1882(95.9)$ & $3204(96.0)$ \\
\hline Country of birth-Australia & $1061(77.8)$ & $1412(72.4)$ & $2473(74.6)$ \\
\hline \multicolumn{4}{|l|}{ Marital status } \\
\hline Single & $257(18.9)$ & $193(9.9)$ & $450(13.6)$ \\
\hline Steady relationship & $99(7.3)$ & $26(1.3)$ & $125(3.8)$ \\
\hline Married or De facto relationship & $895(65.9)$ & $1375(70.7)$ & $2270(68.7)$ \\
\hline Separated & $25(1.8)$ & $58(3.0)$ & $83(2.5)$ \\
\hline Divorced & $68(5.0)$ & $187(9.6)$ & $255(7.7)$ \\
\hline Widowed & $13(1.0)$ & $83(4.3)$ & $96(2.9)$ \\
\hline \multicolumn{4}{|l|}{ Education } \\
\hline No qualifications & $57(4.2)$ & 209 (10.8) & $266(8.1)$ \\
\hline School/Intermediate Certificate & $83(6.1)$ & $259(13.4)$ & $342(10.4)$ \\
\hline High School/Leaving Certificate & $261(19.2)$ & $370(19.1)$ & $631(19.1)$ \\
\hline Trade/Apprenticeship & $95(7.0)$ & $167(8.6)$ & $262(7.9)$ \\
\hline Certificate/Diploma & $293(21.5)$ & $428(22.1)$ & $721(21.6)$ \\
\hline University degree & $341(25.1)$ & $241(12.4)$ & $582(17.7)$ \\
\hline Higher university degree & $190(14.0)$ & $162(8.4)$ & $352(10.5)$ \\
\hline \multicolumn{4}{|l|}{ Occupation } \\
\hline Unemployed & $86(6.4)$ & $151(7.8)$ & $237(7.2)$ \\
\hline Full time student & $82(6.1)$ & $13(0.7)$ & $95(2.9)$ \\
\hline Retired & $134(9.9)$ & 744 (38.5) & $878(26.8)$ \\
\hline Homemaker/Carer/Nolunteer & $106(7.8)$ & $168(8.7)$ & $274(8.4)$ \\
\hline Labourer & $66(4.9)$ & $82(4.2)$ & $148(4.5)$ \\
\hline Clerical/Sales/Service & $222(16.4)$ & $221(11.5)$ & $443(13.5)$ \\
\hline Tradesperson & $78(5.8)$ & $84(4.4)$ & $162(4.9)$ \\
\hline Associate professional & $158(11.7)$ & $152(7.9)$ & $310(9.4)$ \\
\hline Professional & $368(27.2)$ & $240(12.4)$ & $608(18.5)$ \\
\hline Director & $37(2.7)$ & $38(2.0)$ & $75(2.3)$ \\
\hline \multicolumn{4}{|l|}{ Annual household income (\$) } \\
\hline$\leq 20,000$ & $162(12.3)$ & $434(23.7)$ & $596(18.9)$ \\
\hline $20,001-40,000$ & $144(10.9)$ & $415(22.7)$ & $559(17.8)$ \\
\hline $40,001-60,000$ & $218(16.6)$ & $363(19.8)$ & $581(18.5)$ \\
\hline $60,001-100,000$ & $358(27.2)$ & $341(18.6)$ & $699(22.2)$ \\
\hline $100,001-150,000$ & $246(18.7)$ & $181(9.9)$ & $427(13.6)$ \\
\hline$>150,000$ & $187(14.2)$ & $93(5.1)$ & $280(8.9)$ \\
\hline \multicolumn{4}{|l|}{ Geographical location } \\
\hline Metropolitan & $793(58.7)$ & $907(47.0)$ & $1700(51.8)$ \\
\hline Regional & $369(27.3)$ & $555(28.8)$ & $924(28.2)$ \\
\hline Rural & $186(13.8)$ & $464(24.0)$ & $650(19.8)$ \\
\hline
\end{tabular}

*Total $\mathrm{N}$ reported in this table not always consistent with total sample size due to missing data on some items 
interview sessions enabled participants to "have a voice", expressing their thoughts, opinions, feelings and experiences of living with diabetes and healthcare provision.

The Diabetes MILES Study is now an international collaborative, with several colleagues making preparations to undertake similar initiatives in their own countries. Under the leadership of Prof Frans Pouwer of Tilburg University, the first to get underway is Diabetes MILES-The Netherlands, which completed its data collection in October 2011. Both datasets have included a core set of questions and measures (identified in Table 1 ) in order to have sufficient commonality of variables to enable meaningful international comparisons and pooling of data. Those interested in joining the Diabetes MILES Study International Collaborative are invited to contact Prof Jane Speight or Prof Frans Pouwer.

\section{Limitations}

Surveying NDSS registrants who have consented to be contacted about research may not provide a fully representative sample of people with diabetes [54]. It is estimated that up to $50 \%$ of Australians with type 2 diabetes are undiagnosed, do not know they have the condition, and therefore are not on the register [55]. Registration information may include inaccurate or outdated details, such as diagnosis (e.g. type 1 when actually type 2 insulin-treated), treatment or demographics. The NDSS database is routinely cleansed, at least every six months, to correct or remove inaccurate age listings, addresses and update registrant deaths. However, in spite of this, 541 survey packages were returned to sender, because the addressee was either no longer residing at the address or was deceased.

Among the random sample of 15,000 registrants, $1,556(10 \%)$ were listed as having carers. Two-thirds of carers $(n=1,023)$ were for registrants listed as having type 1 diabetes. In the instance where a carer was listed, the survey was automatically addressed to the carer, as is the default system on the NDSS database. In some instances, the carer listing was some years out of date. As such, some surveys may have been ignored, possibly lowering the response rate, simply due to the listed carer no longer being responsible for, living with, or in contact with the registrant.

Men account for 53\% of NDSS adult registrants, and our sample included only $46 \%$ men. However, given that men are often more reluctant to participate in research (especially of a psychosocial nature), we were satisfied with this response. Further, although more than half of our sample were from just two of the eight Australian states and territories (namely New South Wales and Victoria), this reflects the proportion of NDSS registrants who reside in these states.
People of ATSI descent were under-represented in our sample, as were people of lower socioeconomic backgrounds, and people whose main language was not English. Diabetes MILES-Australia as it is described here was not designed specifically to meet the needs of people from culturally and linguistically diverse backgrounds, nor was it available in other languages, and so this result is unsurprising. Future Diabetes MILES-Australia initiatives may be tailored to meet the needs of these sub-populations to improve the accessibility of the study for these groups. However, reflective of the broader Australian population, a quarter of our sample indicated that they were born abroad.

The online survey was more likely to be completed by people with type 1 diabetes, women, younger adults, and those from Victoria or New South Wales. With the research team based in Victoria, there were more opportunities to advertise in Victorian media than in other states. Also, there were more opportunities to advertise in media aimed at adults with type 1 diabetes. Although older adults had lower rates of participation in the online survey than their younger counterparts, more than $20 \%$ of the online survey sample was aged over 55 years, and those who took part spanned the whole eligible age range (18-70 years), suggesting that online research is not inaccessible to older adults.

\section{Conclusions}

Diabetes MILES-Australia represents a major achievement in the study of diabetes in Australia, where there has been limited published research on the psychosocial and behavioural aspects of this condition. For the first time, an in-depth study has been conducted at a national level, which has the potential to provide much needed data on a range of important psychological outcomes hitherto neglected. Diabetes MILES-Australia also represents the baseline of a longitudinal cohort study, which will enable prospective investigation of psychological outcomes and how they relate to the natural history of diabetes, its treatment and the onset of complications and other comorbidities.

\section{Endnotes}

${ }^{a}$ State-based data accurate as of 30 June $2011 .{ }^{\mathrm{b}}$ Gender-based data accurate at December 2010.

\section{Abbreviations}

ANOVA: Analysis of variance; ATSI: Aboriginal or torres strait islander; CD: Cognitive debriefing; CRO: Contract research organisation; DAWN: Diabetes attitudes wishes and needs study; MILES: Management and impact for longterm empowerment and success; NDSS: National diabetes services scheme; SPSS: Statistical package for the social sciences. 


\section{Acknowledgements}

The Diabetes MILES-Australia 2011 Survey was funded by a National Diabetes Services Scheme (NDSS) Strategic Development Grant. The NDSS is an initiative of the Australia Government administered by Diabetes Australia. This funding supported the part-time employment of EHT and JB as well as the conduct of the data collection (including distribution, return and scanning of postal surveys; the development of the online survey). The contributions of JS and $\mathrm{CH}$ were supported by the core funding provided by Diabetes Australia-Vic and Deakin University to The Australian Centre for Behavioural Research in Diabetes.

In addition, Diabetes MILES-Australia received sponsorship from sanofi aventis to support the development of the study website http://www. diabetesMILES.org and miscellaneous activities.

We thank the many people with diabetes who took part in the cognitive debriefing interviews and the Diabetes MILES-Australia 2011 Survey. We acknowledge the Diabetes MILES-Australia Reference Group for their generous advice throughout the study and for their continued collaboration on the dissemination of findings. We thank Jennifer Halliday and Jasmin Schabert from The Australian Centre for Behavioural Research in Diabetes for their contributions to the cognitive debriefing interviews and processing of return postal surveys. We also thank Luke Barisic from the School of Psychology, Deakin University for programming the online survey. Finally, we thank the Diabetes Australia-Vic mailroom coordinators and volunteers for kindly undertaking the survey packaging and distribution.

\section{Author details}

${ }^{1}$ The Australian Centre for Behavioural Research in Diabetes, Diabetes Australia-Vic, 570 Elizabeth Street, Melbourne, VIC 3000, Australia. ${ }^{2}$ Centre for Mental Health and Wellbeing Research, School of Psychology, Deakin University, Burwood, VIC 3125, Australia. ${ }^{3}$ AHP Research, Hornchurch, Essex, UK. ${ }^{4}$ Center of Research on Psychology in Somatic diseases (CoRPS) FSW, Tilburg University, Warandelaan 2, 5037 AB Tilburg, The Netherlands.

\section{Authors' contributions}

JS conceived The Diabetes MILES Study, and together with FP developed The Diabetes MILES Study International Collaborative. JS is principal investigator of Diabetes MILES-Australia; she developed the proposal and designed the study; she took overall responsibility for the development of survey content, and supervision of the research team; she produced the first draft of this manuscript. JB contributed to the development of survey content, conducted data cleaning and analyses, and contributed substantially to the development of this manuscript. EHT was the project manager; she conducted the literature searches, liaised with reference group members, conducted CD interviews, contributed to the development of survey content, managed the survey data collection, and conducted data cleaning and analyses. $\mathrm{CH}$ provided expert advice throughout the data cleaning process and contributed substantially to the development of this manuscript. All authors commented on the initial draft and approved the final manuscript.

\section{Competing interests}

The authors declare that they have no competing interests.

Received: 22 December 2011 Accepted: 12 February 2012 Published: 12 February 2012

\section{References}

1. Zimmet PZ: Diabetes epidemiology as a tool to trigger diabetes research and care. Diabetologia 1999, 42(5):499-518.

2. Wild SH, Roglic G, Green A, Sicree R, King H: Global prevalence of diabetes: estimates for the year 2000 and projections for 2030. Diabetes Care 2004, 27(5):1047-1053.

3. Funnell MM, Anderson RM: Empowerment and self-management of diabetes. Clin Diab 2004, 22(3):123-127.

4. Rubin RR, Peyrot M: Quality of life and diabetes. Diabetes Metab Res Rev 1999, 15(3):205-218.

5. Bradley C, Speight J: Patient perceptions of diabetes and diabetes therapy: assessing quality of life. Diabetes Metab Res Rev 2002, 18:(S3): S64-S69.

6. Fisher L, Skaff MM, Mullan JT, Arean P, Glasgow R, Masharani U: A longitudinal study of affective and anxiety disorders, depressive affect and diabetes distress in adults with type 2 diabetes. Diabet Med 2008 25(9):1096-1101.

7. de Groot M, Anderson R, Freedland KE, Clouse RE, Lustman PJ: Association of depression and diabetes complications: a meta-analysis. Psychosom Med 2001, 63(4):619-630.

8. Alberti G: The DAWN (Diabetes Attitudes, Wishes and Needs) study. Pract Diabetes Int 2002, 19:22-24

9. Rubin RR, Peyrot M, Siminerio LM: Health care and patient-reported outcomes: results of the cross-national Diabetes Attitudes, Wishes, and Needs study. Diabetes Care 2006, 29(6):1249-1255.

10. Skovlund SE, Peyrot M: The Diabetes Attitudes, Wishes, and Needs (DAWN) Program: a new approach to improving outcomes of diabetes care. Diabetes Spectr 2005, 18(3):136-142.

11. Peyrot M, Rubin RR, Lauritzen T, Snoek FJ, Matthews DR, Skovlund SE: Psychosocial problems and barriers to improved diabetes management: results of the Cross-National Diabetes Attitudes, Wishes and Needs (DAWN) Study. Diabet Med 2005, 22(10):1379-1385.

12. Peyrot M, Rubin RR, Lauritzen $T$, Skovlund SE, Snoek FJ, Matthews DR, Landgraf R, Kleinebreil L: Resistance to insulin therapy among patients and providers: results of the cross-national Diabetes Attitudes, Wishes, and Needs study. Diabetes Care 2005, 28(11):2673-2679.

13. Donald M, Dower J, Ware R, Mukandi B, Pearekh S, Bain C: Living with diabetes: Rationale, study design and baseline characteristics for an Australian prospective cohort study. BMC Public Health 2011.

14. World Health Organization: Health education in self-care: Possibilities and limitations Geneva: World Health Organization; 1983.

15. Barnard KD, Skinner TC, Peveler R: The prevalence of co-morbid depression in adults with Type 1 diabetes: systematic literature review. Diabet Med 2006, 23(4):445-448.

16. Ali S, Stone MA, Peters $J$, Davies MJ, Khunti K: The prevalence of comorbid depression in adults with Type 2 diabetes: a systematic review and meta-analysis. Diabet Med 2006, 23(11):1165-1173.

17. DAFNE Study Group: Training in flexible, intensive insulin management to enable dietary freedom in people with type 1 diabetes: dose adjustment for normal eating (DAFNE) randomised controlled trial. $\mathrm{Br}$ Med J 2002, 325(7367):746-749

18. Speight J, Amiel S, Bradley C, Heller S, James P, Oliver L, Roberts S, Rogers H, Taylor C, Thompson G: The Dose Adjustment For Normal Eating (DAFNE) trial: improvements in HbA1c still apparent and quality of life benefits well-maintained at 4-year follow-up. Diabetes Res Clin Pract 2010, 89:22-29.

19. Anderson RM, Funnell MM: Patient empowerment: myths and misconceptions. Patient Educ Couns 2010, 79(3):277-282.

20. Wilson P: More than half of diabetic patients do not get recommended annual tests. BMJ 2010, 340:(c3228).

21. Broadbent E, Donkin L, Stroh JC: Illness and treatment perceptions are associated with adherence to medications, diet, and exercise in diabetic patients. Diabetes Care 2011, 34(2):338-340.

22. Yi JP, Vitaliano PP, Smith RE, Yi JC, Weinger $K$ : The role of resilience on psychological adjustment and physical health in patients with diabetes. BrJ Heal Psychol 2008, 13(2):311-325.

23. de Ridder $D$, Fournier $M$, Bensing J: Does optimism affect symptom report in chronic disease?: what are its consequences for self-care behaviour and physical functioning? J Psychosom Res 2004, 56(3):341-350.

24. van Dam HA, van der Horst FG, Knoops L, Ryckman RM, Crebolder HFJM, van den Borne BHW: Social support in diabetes: a systematic review of controlled intervention studies. Patient Educ Couns 2005, 59(1):1-12.

25. Skinner TC, John M, Hampson SE: Social support and personal models of diabetes as predictors of self-care and well-being: a longitudinal study of adolescents with diabetes. J Pediatr Psychol 2000, 25(4):257-267.

26. Gale E: How to survive diabetes. Diabetologia 2009, 52(4):559-567.

27. Speight J, Woodcock A, Reaney M, Amiel S, Johnson P, Parrott N, Rutter M, Senior P, Smith R, Shaw J: 'The QoL-Q Diabetes'-a novel instrument to assess quality of life for adults with type 1 diabetes undergoing complex interventions including transplantation. Diabet Med 2010, 27 (Suppl 1):3-4.

28. Polonsky WH, Fisher L, Earles J, Dudl RJ, Lees J, Mullan J, Jackson RA: Assessing psychosocial distress in diabetes: development of the diabetes distress scale. Diabetes Care 2005, 28(3):626-631. 
29. Polonsky WH, Anderson BJ, Lohrer PA, Welch G, Jacobson AM, Aponte JE, Schwartz CE: Assessment of diabetes-related distress. Diabetes Care 1995, 18(6):754-760

30. International Wellbeing Group: Personal Wellbeing Index Melbourne: Australian Centre on Quality of Life, Deakin University; 2006.

31. Bech P: Measuring the dimension of psychological general well-being by the WHO-5. Qual Life Newsl 2004, 32:15-16.

32. Kroenke K, Spitzer RL, Williams JBW: The PHQ-9. J Gen Intern Med 2001, 16(9):606-613.

33. Spitzer RL, Kroenke K, Williams JBW, Lowe B: A brief measure for assessing generalized anxiety disorder: the GAD-7. Arch Intern Med 2006, 166(10):1092.

34. Speight J, Barandse S, Bradley C: The W-BQ 28: further development of the well-being questionnaire to include diabetes-specific as well a generic subscale and new stress subscales. Proc Br Psychol Soc 2000, 8(1):21.

35. Herdman M, Gudex C, Lloyd A, Janssen M, Kind P, Parkin D, Bonsel G, Badia X: Development and preliminary testing of the new five-level version of EQ-5D (EQ-5D-5L). Quality of Life Research

36. McCormack LA, Williams-Piehota PA, Bann CM, Burton J, Kamerow DB, Squire C, Fisher E, Brownson CA, Glasgow RE: Development and validation of an instrument to measure resources and support for chronic illness self-management. Diabetes Educ 2008, 34(4):707-718

37. Anderson RM, Fitzgerald JT, Gruppen LD, Funnell MM, Oh MS: The Diabetes Empowerment Scale-Short Form (DES-SF). Diabetes Care 2003, 26(5):1641-1642.

38. Tang TS, Brown MB, Funnell MM, Anderson RM: Social support, quality of life, and self-care behaviors among African Americans with type 2 diabetes. Diabetes Educ 2008, 34(2):266-276.

39. Paddison C: Family support and conflict among adults with type 2 diabetes: developing and testing of a new measure. Eur Diabetes Nurs 2010, 7(1):29-33.

40. Australian Institute of Health and Welfare (AlHW): National Health Data Dictionary. Version 8.0. AlHW Catalogue No. HWI 18 Canberra: AlHW; 1999

41. Horne R, Weinman J: Patients' beliefs about prescribed medicines and their role in adherence to treatment in chronic physical illness. $J$ Psychosom Res 1999, 47(6):555-567.

42. Gold AE, Macleod KM, Frier BM: Frequency of severe hypoglycemia in patients with type 1 diabetes with impaired awareness of hypoglycemia. Diabetes Care 1994, 17(7):697-703.

43. Speight J, Barendse SM, Singh H, Amiel SA, Elliot J, Evans M, Flanagan D, Frier BM, Heller SR, Kerr D, et al: The hypo awareness questionnaire: design of a novel measure of awareness of hypoglycaemia for use in the UK Hypo COMPaSS trial. Diabetes 2010, UK: 3-5 March 2010; Liverpool.

44. Cox DJ, Irvine A, Gonder-Frederick L, Nowacek G, Butterfield J: Fear of hypoglycemia: quantification, validation, and utilization. Diabetes Care 1987, 10(5):617-621.

45. Craig CL, Marshall AL, Sjostrom M, Bauman AE, Booth ML, Ainsworth BE, Pratt M, Ekelund U, Yngve A, Sallis JF, et al: International physical activity questionnaire: 12-country reliability and validity. Med Sci Sports Exerc 2003, 35(8):1381-1395.

46. Snoek F, Skovlund S, Pouwer F: Development and validation of the insulin treatment appraisal scale (ITAS) in patients with type 2 diabetes. Health Qual Life Outcomes 2007, 5(1):69.

47. Scheier M, Carver C: Distinguishing optimism from neuroticism (and trait anxiety, self-mastery, and self-esteem): a re-evaluation of the life orientation test. J Pers Soc Psychol 1994, 67:1063-1078.

48. Schwarzer R, Jerusalem M: Generalized self-efficacy scale. In Measures in health psychology: a users portfolio Causal and control beliefs. Edited by: Weinman J, Wright S, Johnson M. Windsor: NFER-NELSON; 1995:35-137.

49. Rosenberg M: Society and the adolescent child Princeton: Princeton University Press; 1965.

50. Broadbent E, Petrie KJ, Main J, Weinman J: The Brief Illness Perception Questionnaire. J Psychosom Res 2006, 60(6):631-637.

51. Horne R, Weinman J, Hankins M: The beliefs about medicines questionnaire: the development and evaluation of a new method for assessing the cognitive representation of medication. Psychol Heal 1999, 14:1-24.

52. Lempers JD, Clark-Lempers D, Simons RL: Economic hardship, parenting, and distress in adolescence. Child Development 1989, 60:25-39.

53. Australian Bureau of Statistics (ABS): Migration Canberra: ABS; 2008, 09
54. David $M$, Ware $R$, Donald $M$, Alati R: Assessing generalisability through the use of disease registers: findings from a diabetes cohort study. BMJ Open 2011, 1:(1).

55. Dunstan DW, Zimmet PZ, Welborn TA, de Courten MP, Cameron AJ Sicree RA, Dwyer T, Colagiuri S, Jolley D, Knuiman M: The rising prevalence of diabetes and impaired glucose tolerance: the Australian diabetes, obesity and lifestyle study. Diabetes Care 2002, 25(5):829-834.

\section{Pre-publication history}

The pre-publication history for this paper can be accessed here: http://www.biomedcentral.com/1471-2458/12/120/prepub

doi:10.1186/1471-2458-12-120

Cite this article as: Speight et al:: Diabetes MILES-Australia (management and impact for long-term empowerment and success): methods and sample characteristics of a national survey of the psychological aspects of living with type 1 or type 2 diabetes in Australian adults. BMC Public Health 2012 12:120.

\section{Submit your next manuscript to BioMed Central and take full advantage of:}

- Convenient online submission

- Thorough peer review

- No space constraints or color figure charges

- Immediate publication on acceptance

- Inclusion in PubMed, CAS, Scopus and Google Scholar

- Research which is freely available for redistribution

Submit your manuscript at www.biomedcentral.com/submit
Biomed Central 